\title{
Adalimumab regulates intracellular TNFa production in patients with rheumatoid arthritis
}

\author{
Carlos Zamora-Atenza ${ }^{1+}$, Cesar Diaz-Torne ${ }^{2 \dagger}$, Carme Geli ${ }^{2}$, Cesar Diaz-Lopez ${ }^{2}$, M Angels Ortiz ${ }^{1}$, Patricia Moya ${ }^{2}$, \\ Ivan Castellví ${ }^{2}$, Juan C Nieto ${ }^{1}$, Elisabet Cantó ${ }^{1}$, Jordi Casademont ${ }^{2}$, Candido Juarez ${ }^{3}$, Josep M Llobet ${ }^{2}$ \\ and Silvia Vidal ${ }^{*}$
}

\begin{abstract}
Introduction: Adalimumab is a fully human anti-tumor necrosis factor a (anti-TNFa) monoclonal antibody that specifically blocks the interaction of TNFa with its receptors. It binds both soluble and transmembrane TNFa. We hypothesized that blocking these TNFa signals regulates the altered TNFa production in rheumatoid arthritis (RA) patients.
\end{abstract}

Methods: We compared, by flow cytometry, Toll-like receptor induction levels of membrane and intracellular TNFa in monocytes (iTNFa + CD14+ cells) from 12 patients before and after adalimumab treatment with those from 5 healthy donors.

Results: Before starting the treatment, the percentage of iTNFa+CD14+ cells in the RA patients was significantly lower than that in healthy donors (mean $\pm \mathrm{SEM}=33.16 \pm 4.82 \%$ vs $66.51 \pm 2.4 \%, P<0.001$ ). When we added in vitro TNFa to healthy donor culture cells, levels of iTNFa+CD14+ cells decreased, suggesting that the TNFa signal was responsible for the iTNFa+CD14+ cell downregulation observed in the RA patients. After 2, 6 and 12 adalimumab injections, we observed significant blocking of membrane and soluble TNFa and a progressive increase in iTNFa+CD14+ cells in ten patients with a good to moderate response as defined by the European League Against Rheumatism (EULAR) criteria. Levels of iTNFa+CD14+ cells after 12 injections in these 10 patients were comparable to levels in healthy donors. In two patients, iTNFa+CD14+ cell upregulation was not observed, and their EULAR-defined responses had not improved. The first patient developed antiadalimumab antibodies, explaining why adalimumab was not able to block membrane and soluble TNFa. In the second patient, adalimumab was discontinued because of adverse effects, which led to a decrease in iTNFa+ CD14+ cells to levels measured before treatment.

Conclusions: Our findings suggest that adalimumab treatment in RA patients can return iTNFa levels to those of healthy donors. This effect was not observed in the presence of neutralizing antiadalimumab antibodies.

\section{Introduction}

Tumor necrosis factor $\alpha(\mathrm{TNF} \alpha)$ is a proinflammatory cytokine produced mainly by activated monocytes, macrophages, T lymphocytes and natural killer (NK) cells. In target cells, this cytokine plays a key role in apoptosis, cell survival, immunity and inflammation [1-3]. TNF $\alpha$ is initially synthesized and expressed as a transmembrane protein. Its extracellular proportion is released in the form

\footnotetext{
* Correspondence: svidal@santpau.cat

†Equal contributors

'Department of Immunology, Biomedical Research Institut Sant Pau (IBB Sant Pau), C. Antoni M. Claret, 167, 08025 Barcelona, Spain

Full list of author information is available at the end of the article
}

of a soluble $17 \mathrm{kDa}$ molecule when it is cleaved by a metalloproteinase TNF $\alpha$-converting enzyme (TACE) [4].

The level of TNFa in the synovial fluid in rheumatoid arthritis (RA) is high $[5,6]$. In the synovia, TNF $\alpha$ contributes to joint destruction by attracting leukocytes, inducing inflammatory cytokines, upregulating adhesion molecules on endothelial cells and activating the synthesis of metalloproteinases in synovial macrophages, fibroblasts and chondrocytes [7-10]. TNF $\alpha$ also plays a role in osteoclastic bone resorption. It stimulates osteoclastogenesis by differentiating progenitor cells and enhancing the expression of receptor activator of nuclear factor $\mathrm{\kappa} B$ ligand [11].

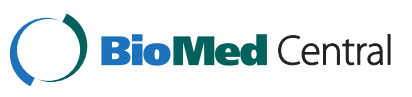

(C) 2014 Zamora-Atenza et al.; licensee BioMed Central Ltd. This is an Open Access article distributed under the terms of the Creative Commons Attribution License (http://creativecommons.org/licenses/by/4.0), which permits unrestricted use, distribution, and reproduction in any medium, provided the original work is properly cited. The Creative Commons Public Domain Dedication waiver (http://creativecommons.org/publicdomain/zero/1.0/) applies to the data made available in this article, unless otherwise stated. 
In view of these findings, it is not surprising that TNF $\alpha$ has become a strategic target in the treatment of RA patients. Adalimumab is a fully human neutralizing antiTNF $\alpha$ monoclonal antibody that specifically blocks the interaction of TNF $\alpha$ with p55 and p75 cell-surface TNF $\alpha$ receptors [12]. By blocking TNF $\alpha$, adalimumab can attenuate cartilage and bone destruction partially through the downregulation of matrix metalloproteinases [13]. Moreover, adalimumab can reduce acute-phase reactants of inflammation [14], inflammatory cytokines [10] and adhesion molecules responsible for leukocyte migration [13]. Studies have shown that adalimumab is effective in preventing joint damage in early RA [15] and improving clinical and laboratory parameters, emphasizing the pivotal role of TNF $\alpha$ in this pathology. However, not all RA patients treated with adalimumab show this clinical response [16].

Although adalimumab has been found to block soluble and transmembrane TNF $\alpha$ [17], whether adalimumab can regulate the production of intracellular TNF $\alpha$ (intracellular TNF $\alpha$ ) on monocytes is unknown. Our aim in this study was to determine whether blocking TNF $\alpha$ signals regulates the TNF $\alpha$ production in patients with RA.

\section{Methods}

\section{Samples}

Heparinized blood obtained from healthy donors (HDs) $(n=5)$, patients with active RA who had never received biological therapy $(n=12)$, RA patients in remission or with low activity who were being treated with methotrexate $(n=3)$ and similar patients treated with infliximab $(n=3)$ was collected in BD Vacutainer tubes (BD Pharmingen, Franklin Lakes, NJ, USA). Diagnosis of RA was based on the American College of Rheumatology criteria [18]. Disease activity was measured using the Disease Activity Score in 28 joints erythrocyte sedimentation rate (DAS28-ESR) [19]. Table 1 shows demographic data, clinical parameters and laboratory values of patients with active RA who were receiving adalimumab treatment every 2 weeks. We collected blood from RA patients after two (4 weeks), six (12 weeks) and twelve (24 weeks) injections of adalimumab. To determine the effectiveness of adalimumab treatment, we evaluated clinical improvement using the European League Against Rheumatism (EULAR) response criteria [20]. We also collected blood from three methotrexate-treated RA patients over the course of more than 3 years $(E S R($ mean $\pm S D)=36.33 \pm 16.65 \mathrm{~mm} / \mathrm{h}, \mathrm{C}$ reactive protein $(\mathrm{CRP})=18.13 \pm 15.15 \mathrm{mg} / \mathrm{L})$ and three RA patients who had been treated with infliximab for more than 5 years $(E S R=42 \pm 30.34 \mathrm{~mm} / \mathrm{h}, \mathrm{CRP}=9.17 \pm$ $3.32 \mathrm{mg} / \mathrm{L}$ ). Written informed consent was obtained from the participants, and ethical approval of the study was granted by the institutional ethics committee of the Hospital de la Santa Creu i Sant Pau.
Table 1 Baseline characteristics of rheumatoid arthritis patients treated with adalimumab ${ }^{a}$

\begin{tabular}{lc}
\hline Characteristics & Data \\
\hline Gender (\% women) & 92.8 \\
Mean age $( \pm S D)$, yr & $56.6 \pm 13.6$ \\
Mean disease duration $( \pm S D), y r$ & $13.8 \pm 11.2$ \\
Mean RF + and/or ACPA + (\%) & 78.6 \\
Mean concomitant methotrexate (\%) & 64.3 \\
Mean concomitant prednisone (\%) & 64.3 \\
Mean previous DMARDs, number (range) & $3.07(1$ to 5$)$ \\
Mean ESR, mm/h ( \pm SD) & $40.1 \pm 23.6$ \\
Mean CRP, mg/L $( \pm S D)$ & $15.6 \pm 17.8$ \\
Mean DAS28-ESR, IU ( $\pm S D)$ & $5.05 \pm 0.95$ \\
\hline
\end{tabular}

aCPA Anticitrullinated peptide antibodies; CRP, C-reactive protein; DAS28-ESR, Disease Activity Score in 28 joints erythrocyte sedimentation rate; DMARDs, Disease-modifying arthritis drugs; RF, Rheumatoid factor.

\section{Determination of intracellular tumor necrosis factor a production in leukocytes}

Whole blood from HDs and RA patients was cultured in 5-ml polypropylene tubes (BD Biosciences, San Jose, CA, USA) with RPMI 1640 medium, $1 \mu \mathrm{g} / \mathrm{ml}$ lipopolysaccharide (LPS) or $10 \mu \mathrm{g} / \mathrm{ml}$ lipoteichoic acid (LTA) (InvivoGen, San Diego, CA, USA) in the presence of BD GolgiStop ${ }^{\text {тM }}$ Protein Transport Inhibitor (BD Biosciences) for 4 hours. After culturing, cells were stained with anti-CD14-fluorescein isothiocyanate (anti-CD14-FITC) (ImmunoTools, Friesoythe, Germany). Samples were fixed and lysed with FACS Lysing Solution (BD Biosciences) for 10 minutes. Samples were then permeabilized with phosphate-buffered saline plus $0.3 \%$ saponin. After permeabilization, samples were washed and stained with anti-TNF $\alpha$-phycoerythrin (anti-TNF $\alpha-P E)$ (BioLegend, San Diego, CA, USA). iTNF $\alpha$ production was analyzed in CD14+ cells and in CD14neutrophils and lymphocytes by flow cytometry.

\section{Determination of membrane tumor necrosis factor a on monocytes}

Whole blood of HDs and RA patients was cultured in RPMI 1640 medium, LPS $(1 \mu \mathrm{g} / \mathrm{ml})$ or LTA $(10 \mu \mathrm{g} / \mathrm{ml})$ in the presence of $25 \mu \mathrm{l}$ of metalloprotease TNF $\alpha-$ converting enzyme (TACE) inhibitor (Cytognos, Salamanca, Spain). After 4 hours in culture, cells were stained with anti-CD14-FITC and anti-TNF $\alpha$-PE (BioLegend). Samples were then incubated with $2 \mathrm{ml}$ of QUICKLYSIS ${ }^{\mathrm{m}}$ solution (Cytognos). Membrane TNF $\alpha$ (mTNF $\alpha)$ was analyzed on CD14+ cells by flow cytometry. Adalimumab injections blocked mTNF $\alpha$, and only free mTNF $\alpha$ was detected. When patient serum (and consequently adalimumab) was washed out of Toll-like receptor (TLR) ligand cultures, mTNF $\alpha$ was detectable (data not shown). 


\section{Determination of tumor necrosis factor a levels in cultures supernatants}

Whole blood of HDs and RA patients was cultured with medium, LPS $(1 \mu \mathrm{g} / \mathrm{ml})$ or LTA $(10 \mu \mathrm{g} / \mathrm{ml})$ at $5 \% \mathrm{CO}_{2}$ and $37^{\circ} \mathrm{C}$. After 24 hours in culture, supernatants were collected. Soluble TNF $\alpha$ levels were determined using a specific enzyme-linked immunosorbent assay (ELISA) kit according to the manufacturer's instructions (BD Biosciences). TNF $\alpha$ was quantified with standard curves, and the limit of detection was $7.5 \mathrm{pg} / \mathrm{ml}$. Adalimumab injections blocked soluble TNF $\alpha$, and only free soluble TNF $\alpha$ was detected.

\section{Determination of adalimumab levels and antiadalimumab antibodies in serum}

Serum from RA patients was collected and kept at $-80^{\circ} \mathrm{C}$ until use. Adalimumab levels and antiadalimumab antibodies were determined using a specific ELISA kit according to the manufacturer's instructions (Proteomika, Derio, Spain). The limit of detection was $0.15 \mathrm{ng} / \mathrm{ml}$ for adalimu$\mathrm{mab}$ and $0.4 \mathrm{AU} / \mathrm{ml}$ for antiadalimumab antibodies.

\section{Flow cytometry analysis}

iTNF $\alpha$ and mTNF $\alpha$ were analyzed on CD14+ monocytes, and iTNF $\alpha$ was analyzed in neutrophils and lymphocytes gated according to forward-scatter and side-scatter parameters in CD14- cells using a Beckman Coulter FC500 flow cytometer (Beckman Coulter, Barcelona, Spain). We calculated the percentages of positive cells (\% cells) and geometric mean fluorescence intensity (GMFI) of each marker using CXP Software 2.2 (Beckman Coulter). The integrated geometric mean fluorescence intensity (iGMFI) was used to determine the amount of mTNF $\alpha$ produced by CD14+ cells and was calculated by multiplying the percentage of positive cytokine-producing cells by the GMFI [21].

\section{Statistical analysis}

Statistical analyses were performed using paired $t$-tests, $t$-tests and Spearman's correlation in GraphPad Prism 5 software (GraphPad Software, La Jolla, CA, USA). Data are presented as mean and \pm SEM. $P$-values $<0.05$ were considered statistically significant.

\section{Results}

Tumor necrosis factor a production in rheumatoid arthritis patients

iTNF $\alpha$ and mTNF $\alpha$ levels in CD14+ cells and TNF $\alpha$ levels in supernatants of LPS (TLR4 ligand) and LTA (TLR2 ligand) of HDs were compared with those of RA patients. For this purpose, whole-blood cells obtained from HDs and RA patients were cultured with TLR ligands before adalimumab therapy was started.
HDs showed a higher percentage of iTNF $\alpha+$ CD14+ cells than RA patients after LPS or LTA culture (LPS $=66.51 \pm 2.4$ for HDs vs $33.16 \pm 4.82$ for RA patients, $P<0.001$; LTA $=39.92 \pm 1.42$ for HDs vs $17.9 \pm 3.4$ for RA patients, $P<0.01$ ) (Figure $1 \mathrm{~A}$ ). TLR ligand-stimulated neutrophils from HDs showed a higher percentage of iTNF $\alpha+$ than those from RA patients (LPS $=0.81 \pm 0.15 \%$ for HDs vs $0.35 \pm 0.05 \%$ for RA patients, $P<0.01$; LTA $=$ $0.55 \pm 0.1 \%$ for HDs vs $0.21 \pm 0.03 \%$ for RA patients, $P<$ $0.05)$. HDs and RA patients had a similar percentage of iTNF $\alpha+$ lymphocytes $\quad(\mathrm{LPS}=0.20 \pm 0.04 \%$ for HDs vs $020 \pm 0.04 \%$ for RA patients; LTA $=0.10 \pm 0.02 \%$ for HDs vs $0.12 \pm 0.02 \%$ for RA patients).

The percentages of mTNF $\alpha+$ CD14+ cells and the levels of supernatant TNF $\alpha$ in RA patients did not differ from those of HDs after TLR ligand cultures (Figure 1B to D).

\section{Intracellular tumor necrosis factor a production in} rheumatoid arthritis patients after adalimumab treatment We next sought to determine how adalimumab treatment could modify the percentage of iTNF $\alpha$ in CD14+ monocytes of RA patients. Whole blood from RA patients collected after 2, 6 and 12 injections of adalimumab was cultured with TLR ligands, and iTNF $\alpha+\mathrm{CD} 14+$ cell percentages were determined. Twelve injections of adalimumab significantly increased the iTNF $\alpha+$ CD $14+$ percentages in RA patients up to levels of HDs $(33.16 \pm 4.82 \%$ for preinjection vs $53.69 \pm 23.49 \%$ after 12 injections, $P<0.05)$ (Figure 2A). Levels of iTNF $\alpha+$ CD14+ cells increased after two $(48.29 \pm 20.45 \%, P<0.01)$ and six injections $(42.01 \pm 18.93 \%, P<0.05)$. The kinetics were similar in LTA cultures $(17.91 \pm 11.78 \%$ for preinjection vs $32.51 \pm 21.46 \%$ after 12 injections, $P<0.05)$. A higher percentage of iTNF $\alpha+$ neutrophils was observed after 12 infusions of adalimumab (LPS $=0.74 \pm 0.13 \%, P<0.05$; LTA $=0.47 \pm 0.09 \%, P<0.05)$.

To confirm the adalimumab findings with other comparable anti-TNF $\alpha$ treatments, we included RA patients treated with infliximab. The percentages of iTNF $\alpha+$ CD14+ cells were comparable in infliximab-treated patients $(71.53 \pm 1.53 \%)$, in patients treated with adalimumab $(60.68 \pm 5.87 \%)$ and in HDs $(66.51 \pm 2.4 \%)$.

To determine whether the increases in iTNF $\alpha+$ CD14+ cells observed in the RA patients were due to adalimumab treatment or a consequence of the remission state, we analyzed RA patients in methotrexate-induced remission. Percentages of iTNF $\alpha+C D 14+$ cells in RA patients in methotrexate-induced remission were significantly lower than those in RA patients after 12 injections of adalimumab treatment $(28.25 \pm 10.5 \%$ and $60.68 \pm 5.87 \%$, respectively, $P<0.05$ ) (Figure 2A). These low percentages of iTNF $\alpha+\mathrm{CD} 14+$ cells in methotrexate-treated patients were not restored by overnight culture with adalimumab $(23.89 \pm 13.94 \%)$. 


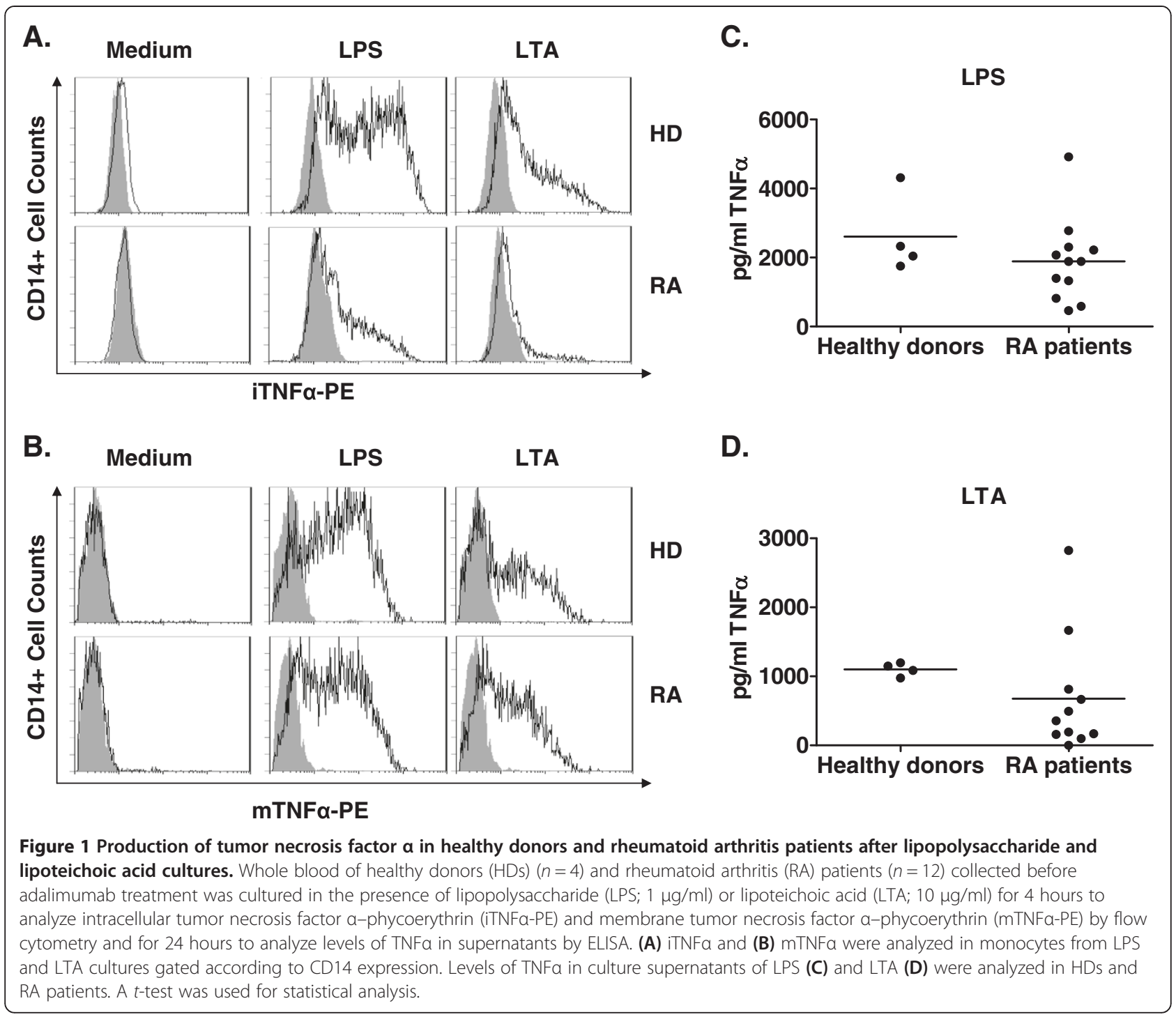

Intracellular tumor necrosis factor a regulation in rheumatoid arthritis patients in good to moderate responders to adalimumab

After 12 injections of adalimumab, ESR, CRP and DAS28ESR were significantly lower than before the injections (respectively, $21.72 \pm 14.83 \mathrm{~mm} / \mathrm{h}, P<0.05 ; 2.64 \pm 2.22 \mathrm{mg} / \mathrm{L}$, $P<0.05$; and $2.89 \pm 0.96 \mathrm{UI}, P<0.001)$. The percentage of iTNF $\alpha+$ CD14+ cells was comparable in HDs and RA patients with a good to moderate EULAR response (10 of 12 patients) after 12 injections of adalimumab (LPS $=60.68 \pm 5.87 \%$ vs $66.51 \pm 2.4 \%$ ). These patients had already presented increased percentages of iTNF $\alpha+$ CD14+ cells after two $(49.13 \pm 7.05 \%)$ and six injections (47.91 \pm 4.09\%) (Figure 2C).

Adalimumab was not effective in two patients. Patient 11 presented a lower percentage of iTNF $\alpha+$ CD14+ cells after LPS and LTA cultures (data not shown) at all postinjection time points than HDs (Figure 2E). Another patient, patient 7 , received the third injection after a 4-week delay due to an infection. The patient then presented adverse effects (allergy), and adalimumab was discontinued. In this patient, the increased percentage of iTNF $\alpha+\mathrm{CD} 14+$ cells and higher EULAR-defined response seen after the first two injections were not observed after the third injection (Figure 2D). Consistent with our observations, DAS28 levels and ESR were inversely correlated with the percentage of iTNF $\alpha+C D 14+$ cells along treatment (DAS28-ESR $=R=-0.445, P=0.0095$; $\mathrm{ESR}=\mathrm{R}=-0.563, P<0.0001)$ in good to moderate EULARdefined response patients.

\section{Adalimumab levels and antiadalimumab antibodies in serum of rheumatoid arthritis patients}

In view of the findings described above, we next compared adalimumab levels and antiadalimumab antibodies in patients 7 and 11 with those in RA patients with good 


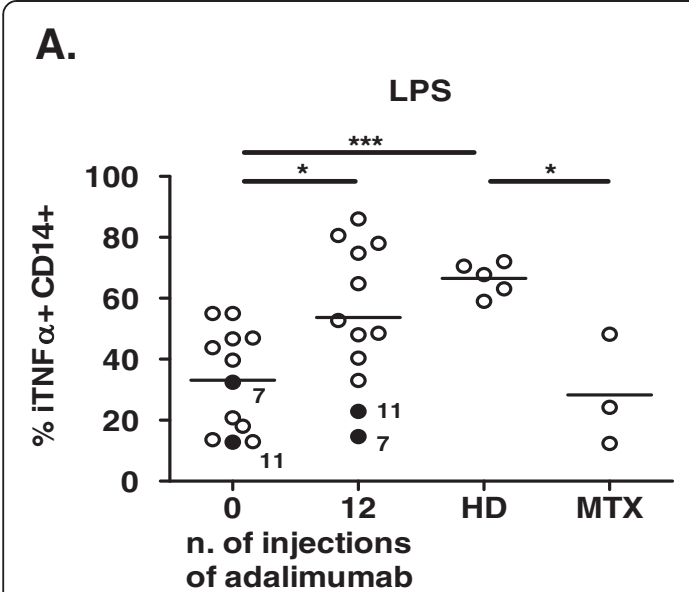

B.

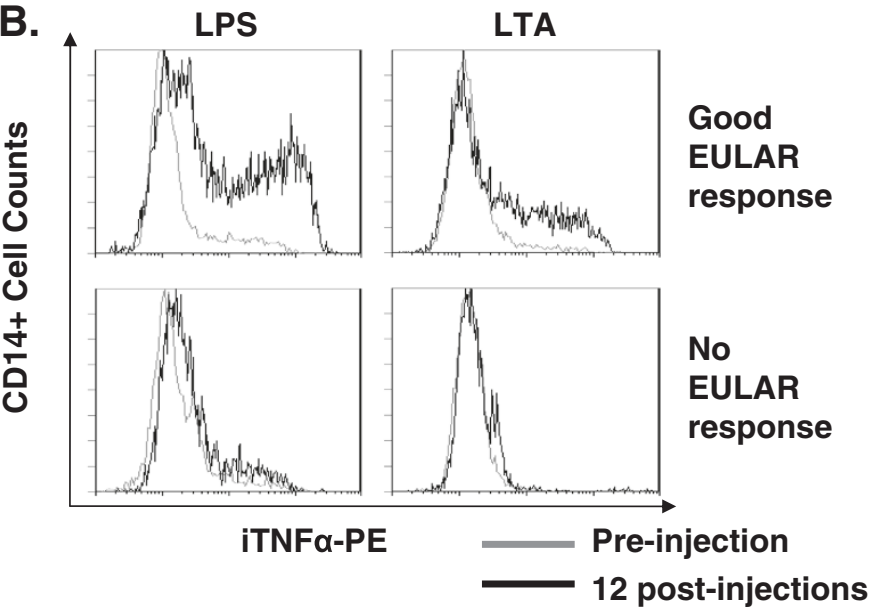

C.

Good/Moderate EULAR response

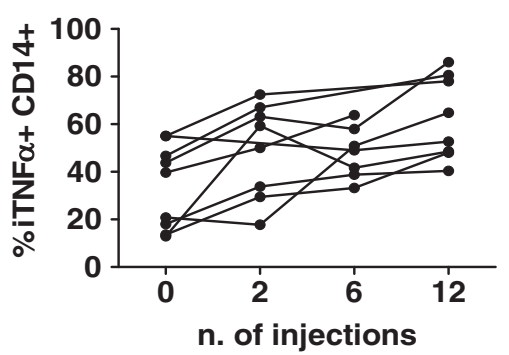

D.

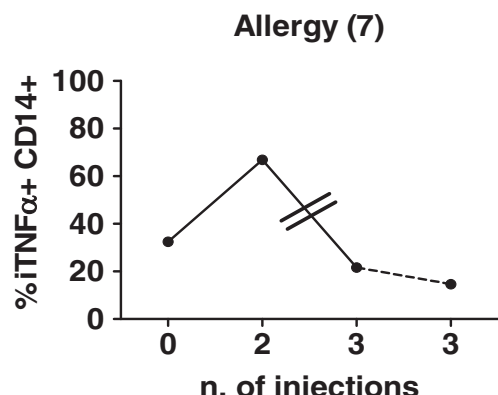

E.

Lack of efficacy (11)

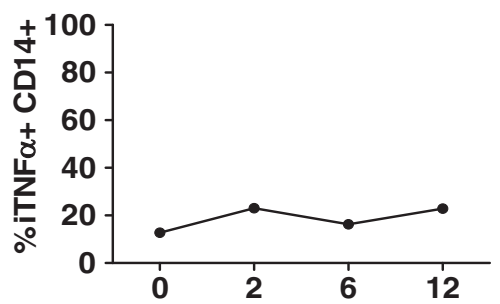

n. of injections

Figure $\mathbf{2}$ Intracellular tumor necrosis factor a production in whole-blood cells from healthy donors and rheumatoid arthritis patients after adalimumab treatment. Intracellular tumor necrosis factor a (iTNFa) production was analyzed on CD14+ cells in rheumatoid arthritis (RA) patients before treatment and after 2, 6 and 12 injections of adalimumab. (A) This graph shows the percentage of iTNFa+ CD14+ after lipopolysaccharide (LPS) culture in patients before and after adalimumab treatment, after methotrexate (MTX) treatment and in healthy donors (HDs). (B) This representative image of flow cytometry results shows the percentage of iTNFa+CD14+ cells after LPS and lipoteichoic acid (LTA) culture in RA patients before and after 12 injections of adalimumab. EULAR, European League Against Rheumatism. (C) This graph shows the percentage of iTNFa+CD14+ cells in LPS culture before and after 2, 6 and 12 injections of adalimumab into RA patients with a good to moderate EULAR-defined response. (D) This graph shows the percentage of iTNFa+ CD14+ cells in LPS culture before and after two and three injections of adalimumab into patient 7. The two lines in this figure correspond to two missed injections of adalimumab. The dashed line corresponds to the suppression of adalimumab. (E) This graph shows percentage of iTNFa+ CD14+ cells in LPS culture before and after 2, 6 and 12 injections of adalimumab into patient 11. A paired $t$-test was used for statistical analysis between RA patients at different time points. A t-test was used for statistical analysis between RA patients and HDs. ${ }^{*} P<0.05,{ }^{* * *} P<0.001$.

to moderate EULAR-defined responses. The seven patients with good to moderate EULAR-defined responses presented therapeutic levels of adalimumab $(>1 \mu \mathrm{g} / \mathrm{ml})$ [22] after 12 injections and did not have detectable antiadalimumab antibody levels in serum (Table 2).

The two patients (patients 7 and 11) who did not show a EULAR-defined response presented different patterns. Although patient 7 showed therapeutic levels of adalimumab after two and three injections, therapy was suspended after the third injection due to allergic reactions. Consequently, at 24 weeks after initiation of treatment (14 weeks from the last adalimumab injection), adalimumab levels were undetectable, coinciding with the downregulation of $i T N F \alpha+C D 14+$ percentages to levels comparable to those before treatment. Patient 11 presented no clinical response to adalimumab at any moment during follow-up, coinciding with undetectable levels of adalimumab in serum after 2, 6 and 12 injections. These undetectable levels of adalimumab were a consequence of the high titers of antiadalimumab antibodies after the second injection (Table 2). No patients had detectable levels of adalimumab antibodies in serum before adalimumab treatment.

Free tumor necrosis factor a levels at the membrane of monocytes and in the culture supernatants from rheumatoid arthritis patients

We evaluated the iGMFI of mTNF $\alpha$ on monocytes and soluble TNF $\alpha$ in TLR ligand culture supernatants after 2, 6 and 12 injections of adalimumab. mTNF $\alpha+\mathrm{CD} 14+$ cell iGMFI decreased after two injections in all patients 
Table 2 Adalimumab and antiadalimumab antibody levels in serum of rheumatoid arthritis patients ${ }^{a}$

\begin{tabular}{|c|c|c|c|c|c|c|c|}
\hline \multirow[b]{2}{*}{ Patient } & \multicolumn{3}{|c|}{ Adalimumab levels (mg/ml) } & \multicolumn{3}{|c|}{ Antiadalimumab levels (AU/ml) } & \multirow{2}{*}{$\begin{array}{c}\text { Discontinuation } \\
\text { cause }\end{array}$} \\
\hline & $4 \mathrm{wk}$ & $12 \mathrm{wk}$ & $24 \mathrm{wk}$ & 4 wk & $12 \mathrm{wk}$ & 24 wk & \\
\hline 1 & n.d. & n.d. & n.d. & n.d. & n.d. & n.d. & - \\
\hline 2 & n.d. & n.d. & n.d. & n.d. & n.d. & n.d. & - \\
\hline 3 & n.d. & n.d. & 9.62 & n.d. & n.d. & NG & - \\
\hline 4 & n.d. & n.d. & 10.06 & n.d. & n.d. & NG & - \\
\hline 5 & n.d. & n.d. & 4.9 & n.d. & n.d. & NG & - \\
\hline 6 & n.d. & n.d. & 14.697 & n.d. & n.d. & NG & - \\
\hline 8 & 14 & 14.4 & 24.065 & NG & NG & NG & - \\
\hline 9 & n.d. & n.d. & 39.409 & n.d. & n.d. & NG & - \\
\hline 10 & n.d. & n.d. & n.d. & n.d. & n.d. & n.d. & - \\
\hline 12 & n.d. & n.d. & 8 & n.d. & n.d. & NG & - \\
\hline 7 & 7.8 & 7 & NG & NG & NG & NG & Allergy \\
\hline 11 & NG & NG & NG & 297,268 & 81,833 & 2,925 & Lack of efficacy \\
\hline
\end{tabular}

a.d., Not determined; NG, Negative.

(LPS $=773.7 \pm 212.9$ preinjection, $33.51 \pm 12.03$ for two injections $(P<0.01), 293.3 \pm 265.8$ for six injections, and $112.1 \pm 84.39$ for twelve injections $(P<0.05)$; LTA $=144.4 \pm 43.68$ preinjection, $13.79 \pm 6.63$ for two injections $(P<0.05), 243.4 \pm 210.1$ for six injections and 34.14 \pm 18.27 for twelve injections $(P<0.05)$ ) (Figure $3 \mathrm{~A}$ and $\mathrm{B}$ ). In patient $11, \mathrm{mTNF} \alpha+\mathrm{CD} 14+\mathrm{iGMFI}$ levels decreased after two injections, but increased thereafter to the levels measured before initiation of treatment. As expected, iGMFI levels of mTNF $\alpha+$ on CD14+ cells from RA patients in remission after infliximab were comparable to those from RA patients in remission after adalimumab, but they were significantly different from those of HDs $(41.99 \pm 16.28$ for infliximab, $20.62 \pm 4.02$ for adalimumab and $715.4 \pm 144.6$ for HDs; $P<0.01$ ).

After two injections of adalimumab, levels of free soluble TNF $\alpha$ significantly decreased in supernatants of TLR cultures in all but patient 11 (LPS $=1,888 \pm$ $378.5 \mathrm{pg} / \mathrm{ml}$ preinjection, $338.7 \pm 153.6 \mathrm{pg} / \mathrm{ml}$ for two injections $(P<0.01), 290.5 \pm 219.1 \mathrm{pg} / \mathrm{ml}$ for six injections $(P<0.05)$ and $338.9 \pm 155.4 \mathrm{pg} / \mathrm{ml}$ for twelve injections $(P<0.05) ; \mathrm{LTA}=676.3 \pm 257.4 \mathrm{pg} / \mathrm{ml}$ preinjection, $202.2 \pm$ $125.4 \mathrm{pg} / \mathrm{ml}$ for two injections $(P<0.05), 506.7 \pm 488.6 \mathrm{pg} /$ $\mathrm{ml}$ for six injections, and $54.37 \pm 28.49 \mathrm{pg} / \mathrm{ml}$ for twelve injections $(P<0.05)$ ) (Figure $3 \mathrm{C}$ and $\mathrm{D})$.

\section{Regulation of intracellular tumor necrosis factor a} production by tumor necrosis factor a signaling

We next analyzed how TNF $\alpha$-TNF receptor signaling downregulated iTNF $\alpha$ production in CD14+ cells. Overnight preincubation of whole-blood cells from HDs with recombinant TNF $\alpha(6 \mathrm{ng} / \mathrm{ml})$ decreased the percentage of iTNF $\alpha+$ CD14+ cells in a 4-hour LPS culture
$(88.87 \pm 6.01 \%$ for medium culture vs $11.49+2.11$ for TNF $\alpha$ culture; $P<0.01)$.

To understand the effect of adalimumab on iTNF $\alpha$ regulation by TNF $\alpha$ signaling, we established two conditions. First, we precultured cells with TNF $\alpha$ plus adalimumab $(2 \mu \mathrm{g} / \mathrm{ml})$ overnight before stimulation with LPS plus adalimumab for 4 hours. Adalimumab restored the production of iTNF $\alpha$ in CD14+ monocytes to normal levels $(80.59 \pm 6.79 \%)$. Second, we precultured cells overnight with TNF $\alpha$ before stimulation with LPS in the presence of adalimumab for 4 hours. In this case, adalimumab was not able to restore iTNF $\alpha$ production in CD14+ cells $(13.91 \pm 0.18 \%)$. Preculturing cells with adalimumab did not alter iTNF $\alpha+$ CD14+ percentages (Figure 4).

\section{Discussion}

Our present findings suggest that, as a result of exposure to TNF $\alpha$, cells from patients with active RA had a lower percentage of iTNF $\alpha+$ CD14+ cells compared with HDs. After 12 injections of adalimumab treatment, the percentage of iTNF $\alpha+$ CD14+ cells increased progressively, reaching levels similar to those of HDs. This effective adalimumab-induced iTNF $\alpha+\mathrm{CD} 14+$ upregulation was observed only in RA patients who showed a EULARdefined response. After the first two injections, TNF $\alpha$ on the membrane and in the culture supernatant was effectively blocked by adalimumab in all but one patient, who developed antiadalimumab antibodies.

TNF $\alpha$ plays a key role in RA physiopathology. However, we did not expect patients with active RA to have a lower percentage of iTNF $\alpha+\mathrm{CD} 14+$ cells than HDs after TLR cultures. This finding suggests that monocytes from 

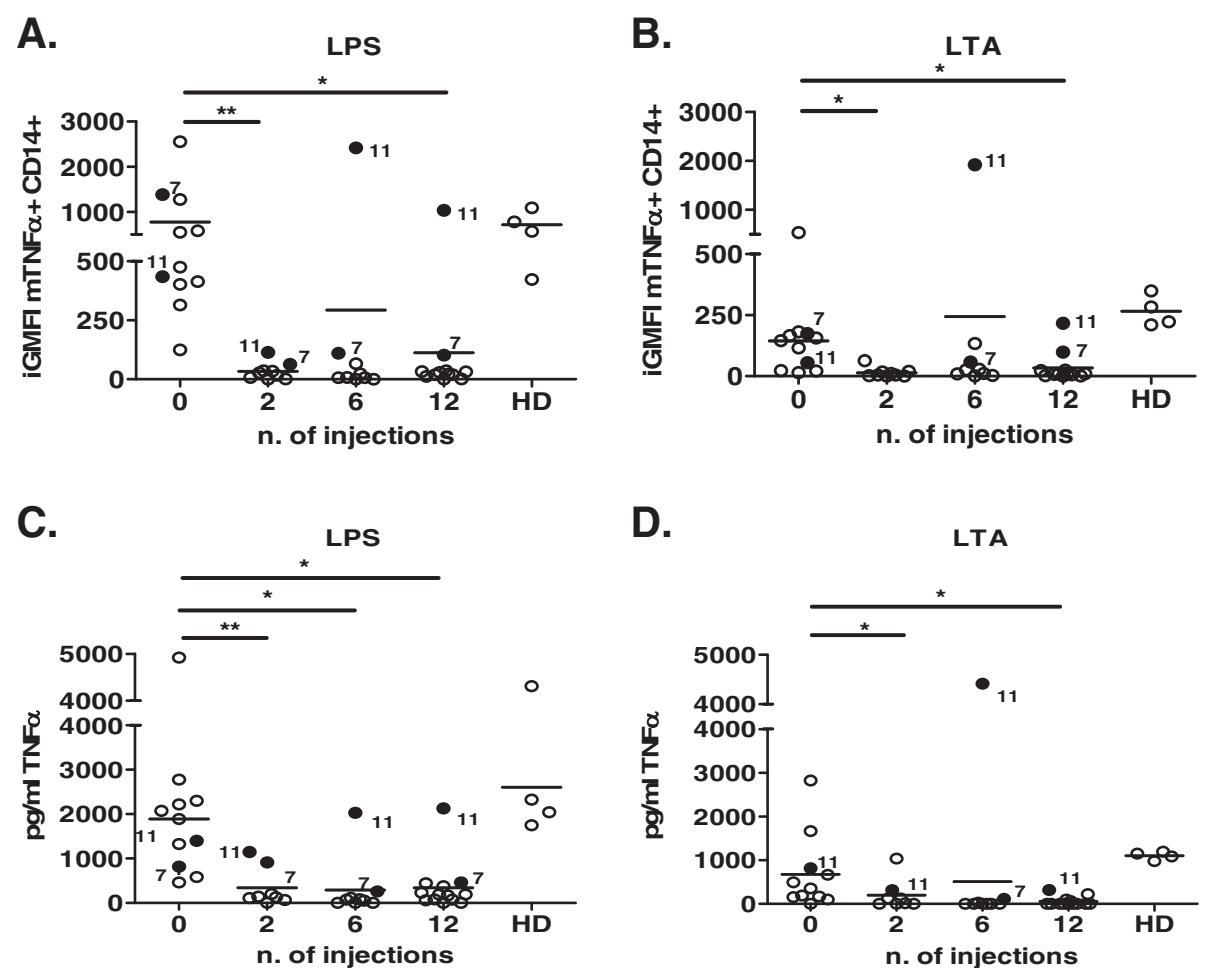

Figure 3 Free tumor necrosis factor a levels on membranes of monocytes and culture supernatants from healthy donors and rheumatoid arthritis patients after adalimumab treatment. Membrane tumor necrosis factor a (mTNFa) levels on monocytes and culture supernatants were analyzed in rheumatoid arthritis (RA) patients before and after 2, 6 and 12 injections of adalimumab. Graphs show integrated geometric mean fluorescence intensity (iGMFI) of mTNFa in healthy donors (HDs) and RA patients after lipopolysaccharide (LPS) culture (A) and lipoteichoic acid (LTA) culture (B). Graphs shows TNFa concentrations ( $\mathrm{pg} / \mathrm{ml}$ ) in healthy donors and RA patients at all time points of adalimumab treatment, after LPS culture (C) and LTA culture (D). A paired t-test was used for statistical analysis between RA patients and number of injections. A t-test was used for statistical analysis between RA patients and healthy donors. ${ }^{*} P<0.05,{ }^{* *} P<0.01$.

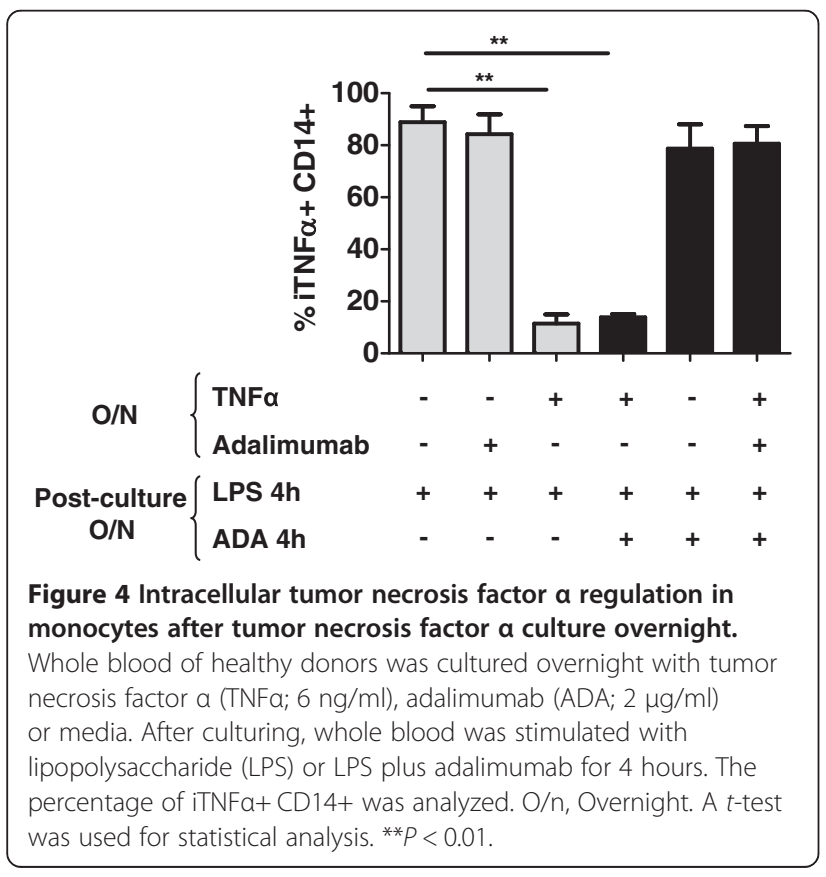

patients with active RA have different regulation of iTNF $\alpha$ production. To understand this unexpected finding, we cultured HD cells with exogenous TNF $\alpha$, which confirmed that TNF $\alpha$ signals induced negative feedback on iTNF $\alpha$ production or increased traffic of iTNF $\alpha$ to the membrane. Other authors have previously observed that TNF $\alpha$ induced tristetrapolin production, which destabilized TNF $\alpha$ mRNA [23]. Our observations therefore suggest that RA cells were exposed to TNF $\alpha$. However, TNF $\alpha$ levels were undetectable in serum from these RA patients. We propose that alternative sources of TNF $\alpha$ for circulating RA cells could be local soluble or membrane TNF $\alpha$ $[5,24]$. On the basis of the results of our present experiments, we cannot exclude the potential that there are additional factors involved in the reduction of iTNF $\alpha+$ CD14+ cells.

We observed that ESR and DAS28-ESR were inversely correlated with the number of iTNF $\alpha+\mathrm{CD} 14+$ cells, suggesting that iTNF $\alpha+C D 14+$ cells and inflammatory activity were robustly associated. We think that the downregulation of iTNF $\alpha+$ CD14+ cells percentage was a regulatory mechanism to control excessive TNF $\alpha$ and its detrimental consequences. 
Adalimumab is currently indicated to reduce signs and symptoms in adult patients with moderately to severely active RA. It induces clinical response, inhibits the progression of joint damage and improves physical function [25]. Here we show that levels of iTNF $\alpha+$ CD14+ cells increased progressively after the first two injections of adalimumab. This effect was not observed in RA patients in remission induced by methotrexate, suggesting that upregulation of iTNF $\alpha+C D 14+$ cells was adalimumab-dependent. In addition, the highest levels of iTNF $\alpha+$ CD14+ cells after 12 injections coincided with the greatest clinical improvement (measured by EULARdefined response), suggesting that proper regulation of iTNF $\alpha$ production in RA patients was associated with a good to moderate EULAR-defined response .

In our in vitro experiments, adalimumab was not able to restore normal iTNF $\alpha+$ CD14+ levels overnight when cells had previously been exposed to TNF $\alpha$, suggesting that, in vivo, normalization of iTNF $\alpha+$ CD14+ cells was due to indirect mechanisms. One possible mechanism is that adalimumab blocks TNF $\alpha$ binding to its receptor [12]. Without TNF $\alpha$ signaling [23], interleukin 1 (IL-1), IL-6, IL-8, granulocyte-macrophage colony-stimulating factor [10] and acute-phase reactants of inflammation (CRP, fibrinogen and ESR) [14] are reduced. This reduction implicates the return of RA cells to a basal state similar to that of cells of HDs and the consequent correction of the percentage of iTNF $\alpha+$ CD14+ cells. Another possible mechanism is that the renovated circulating pool of CD14+ cells has no contact with TNF $\alpha$, because TNF $\alpha$ is blocked [26]. A third possible mechanism is also worthy of mention. Monocytes and macrophages from RA patients are targets of TNF $\alpha$ signals and the major producing cells of TNF $\alpha$, which they present in significant amounts in membrane [27]. Adalimumab has cytotoxic effects on mTNF $\alpha$-expressing cells [28]. However, it takes several days to get rid of all the cells with mTNF $\alpha$. Once they are all eliminated, new CD14+ cells with regular iTNFo production repopulate the system.

We observed that infliximab, another neutralizing anti-TNF $\alpha$ monoclonal antibody, restored the percentages of iTNF $\alpha+C D 14+$ cells to normal values after a long period of therapy. However, in a previous study with infliximab, researchers showed that monocytes produced lower amounts of iTNF $\alpha$ after 24 weeks of treatment than before treatment [29]. This discrepancy in results could be due to clinical and methodological differences. The most crucial difference is that the results described in the previous report were expressed as molecules of equivalent soluble fluorescein per cell, whereas ours are expressed as the percentage of CD14+ monocytes with iTNF $\alpha$. In addition, and in contrast to those authors, we also evaluated iTNF $\alpha$ levels in HDs to establish the normal percentages of iTNF $\alpha+$ CD14 + -producing cells.

It should be noted here that, although infliximab and adalimumab are both TNF $\alpha$-blocking antibodies, they are not fully comparable. Infliximab is administered intravenously at 0,2 and 6 weeks, followed by a maintenance infusion dose every 8 weeks, whereas adalimumab is administered subcutaneously every 15 days. Moreover, infliximab is a chimeric antibody, whereas adalimumab is a fully humanized antibody.

Adalimumab treatments significantly reduced levels of free mTNF $\alpha$ on CD14+ cells and free soluble TNF $\alpha$ in TLR cultures compared to the first injection. This dramatic reduction in mTNF $\alpha$ on cells was due to two activities of adalimumab: (1) its binding blocked TNF signals and (2) it competed with antibodies for flow cytometry detection [17]. A similar conclusion could be reached for soluble TNF $\alpha$ [30]. Unfortunately, our experimental approach does not allow us to establish the fate of mTNF $\alpha$ and soluble TNF $\alpha$ after adalimumab. However, because iTNF $\alpha$ is the source of mTNF $\alpha$ and soluble TNF $\alpha$, we can speculate that iTNF $\alpha, m$ TNF $\alpha$ and soluble TNF $\alpha$ have comparable kinetics.

Not all patients respond to adalimumab therapy [16]. In our study, patient 11 did not respond, and, consequently, no iTNF $\alpha$ regulation in CD14+ cells was observed. The lack of response in this patient was due to the presence of antiadalimumab antibodies after the second injection. Although patient 7 responded to adalimumab and iTNF $\alpha+$ CD14+ cells increased accordingly after two injections, treatment was discontinued after the third injection due to allergy. Consequently, the percentage of iTNF $\alpha+$ CD14+ cells dropped to levels seen before adalimumab therapy was started. We think that, if adalimumab had not been withdrawn, this patient could have had a good or moderate EULAR-defined response.

We hope that our ongoing experiments will allow us to determine whether the increase in iTNF $\alpha+$ CD14+ cells is RA-specific or could be extended to other inflammatory pathologies in which TNF $\alpha$ plays a crucial role. Studying the regulation of iTNF $\alpha+\mathrm{CD} 14+$ cells in RA patients could provide individualized information about the efficacy of adalimumab treatment.

\section{Conclusions}

Our findings suggest that adalimumab treatment in RA patients can return iTNF $\alpha$ levels to those of HDs. This effect was not observed in the presence of neutralizing antiadalimumab antibodies that produced no EULARdefined response. Our future studies of iTNF $\alpha$ in monocytes during treatment with adalimumab therapy in RA patients could provide information about the effectiveness of treatment. 


\section{Abbreviations}

ACPA: Anticitrullinated peptide antibody; CRP: C-reactive protein; DMARD: Disease-modifying antirheumatic drug; ESR: Erythrocyte sedimentation rate; HD: Healthy donor; iGMFI: Integrated geometric mean fluorescence intensity; iTNFa: Intracellular tumor necrosis factor a; LPS: Lipopolysaccharide; LTA: Lipoteichoic acid; mTNFa: Membrane tumor necrosis factor a; RA: Rheumatoid arthritis, RF, rheumatoid factor; TACE: Metalloproteinase tumor necrosis factor a-converting enzyme; TLR: Toll-like receptor; TNFa: Tumor necrosis factor a.

\section{Competing interests}

The authors declare that they have no competing interests.

\section{Authors' contributions}

CZ carried out cell culture and flow cytometry, analyzed and interpreted the experimental and clinical data, participated in the design of the study and drafted and edited the manuscript. CDT collected samples and clinical parameters, analyzed and interpreted the experimental and clinical data and participated in the design of the study. CG, CDL, JC, JLL and PM collected samples and clinical parameters. MAO carried out ELISAs and analysis of data. IC collected samples and clinical parameters and revised several sections of the manuscript. JCN carried out ELISAs and participated in the analysis of flow cytometry data.

EC assisted in the cell culture design and analyzed the experimental data CJ participated in the analysis of experimental data and revised several sections of the manuscript. SV conceived of the study, participated in the design and coordination of the study, analyzed clinical and experimental data and participated in the drafting and editing of the manuscript. All authors read and approved the final manuscript.

\section{Acknowledgements}

We thank Carolyn Newey for helpful editorial assistance. We thank Maite Sanz and Immunology laboratory for their technical collaboration. The work reported has been supported by Abbott Laboratories. SV was supported by "Fondo Investigaciones Sanitarias" and participant in the Program for Stabilization of Investigators of the Direcció i d'Estrategia i Coordinació del Departament Salut de la Generalitat de Catalunya.

\section{Author details}

${ }^{1}$ Department of Immunology, Biomedical Research Institut Sant Pau (IBB Sant Pau), C. Antoni M. Claret, 167, 08025 Barcelona, Spain. ${ }^{2}$ Unit of Rheumatology, Department of Internal Medicine, Hospital de la Santa Creu i Sant Pau, C. Antoni M. Claret, 167, 08025 Barcelona, Spain. ${ }^{3}$ Department of Immunology, Hospital de la Santa Creu i Sant Pau, C. Antoni M. Claret, 167, 08025 Barcelona, Spain.

Received: 23 December 2013 Accepted: 4 July 2014

Published: 18 July 2014

\section{References}

1. Bemelmans $\mathrm{MH}$, van Tits $\sqcup$, Buurman WA: Tumor necrosis factor: function, release and clearance. Crit Rev Immunol 1996, 16:1-11.

2. Bazzoni F, Beutler B: The tumor necrosis factor ligand and receptor families. N Engl J Med 1996, 334:1717-1725.

3. Locksley RM, Killeen N, Lenardo MJ: The TNF and TNF receptor superfamilies: integrating mammalian biology. Cell 2001, 104:487-501.

4. Black RA, Rauch CT, Kozlosky CJ, Peschon JJ, Slack JL, Wolfson MF, Castner BJ, Stocking KL, Reddy P, Srinivasan S, Nelson N, Boiani N, Schooley KA, Gerhart M, Davis R, Fitzner JN, Johnson RS, Paxton RJ, March CJ, Cerretti DP: A metalloproteinase disintegrin that releases tumour-necrosis factor-a from cells. Nature 1997, 385:729-733.

5. Matsuno H, Yudoh K, Katayama R, Nakazawa F, Uzuki M, Sawai T, Yonezawa T, Saeki Y, Panayi GS, Pitzalis C, Kimura T: The role of TNF-a in the pathogenesis of inflammation and joint destruction in rheumatoid arthritis (RA): a study using a human RA/SCID mouse chimera. Rheumatology (Oxford) 2002, 41:329-337.

6. Tetta C, Camussi G, Modena V, Di Vittorio C, Baglioni C: Tumour necrosis factor in serum and synovial fluid of patients with active and severe rheumatoid arthritis. Ann Rheum Dis 1990, 49:665-667.
7. Middleton J, Americh L, Gayon R, Julien D, Aguilar L, Amalric F, Girard JP: Endothelial cell phenotypes in the rheumatoid synovium: activated, angiogenic, apoptotic and leaky. Arthritis Res Ther 2004, 6:60-72.

8. Connor AM, Mahomed N, Gandhi R, Keystone EC, Berger SA: TNFa modulates protein degradation pathways in rheumatoid arthritis synovial fibroblasts. Arthritis Res Ther 2012, 14:R62.

9. Kinne RW, Brauer R, Stuhlmuller B, Palombo-Kinne E, Burmester GR: Macrophages in rheumatoid arthritis. Arthritis Res 2000, 2:189-202.

10. Choy EH, Panayi GS: Cytokine pathways and joint inflammation in rheumatoid arthritis. N Engl J Med 2001, 344:907-916.

11. OG D, Ireland D, Bord S, Compston JE: Joint erosion in rheumatoid arthritis: interactions between tumour necrosis factor a, interleukin 1, and receptor activator of nuclear factor $\mathrm{KB}$ ligand (RANKL) regulate osteoclasts. Ann Rheum Dis 2004, 63:354-359.

12. van de Putte LBA, Salfeld J, Kaymakcalan Z: Adalimumab. In TNF-Inhibition in the Treatment of Rheumatoid Arthritis. Edited by Moreland LW, Emery P. London: Martin Dunitz; 2003:93.

13. den Broeder AA, Joosten LA, Saxne T, Heinegard D, Fenner H, Miltenburg AM, Frasa WL, van Tits $L$, Buurman WA, van Riel PL, van de Putte $L B$, Barrera $P$ : Long term anti-tumour necrosis factor a monotherapy in rheumatoid arthritis: effect on radiological course and prognostic value of markers of cartilage turnover and endothelial activation. Ann Rheum Dis 2002, 61:311-318.

14. HUMIRA (adalimumab): Summary of Product Characteristics [package insert]. Abbott Park, IL: Abbott Laboratories; 2005.

15. Takeuchi T, Yamanaka H, Ishiguro N, Miyasaka N, Mukai M, Matsubara T, Uchida $S$, Akama $H$, Kupper $H$, Arora V Tanaka Y: Adalimumab, a human anti-TNF monoclonal antibody, outcome study for the prevention of joint damage in Japanese patients with early rheumatoid arthritis: the HOPEFUL 1 study. Ann Rheum Dis 2014, 73:536-543.

16. Bartelds GM, Wijbrandts CA, Nurmohamed MT, Stapel S, Lems WF, Aarden L, Dijkmans BA, Tak PP, Wolbink GJ: Clinical response to adalimumab: relationship to anti-adalimumab antibodies and serum adalimumab concentrations in rheumatoid arthritis. Ann Rheum Dis 2007, 66:921-926.

17. Horiuchi T, Mitoma H, Harashima S, Tsukamoto H, Shimoda T: Transmembrane TNF-a: structure, function and interaction with anti-TNF agents. Rheumatology (Oxford) 2010, 49:1215-1228.

18. Arnett FC, Edworthy SM, Bloch DA, MCShane DJ, Fries JF, Cooper NS, Healey LA, Kaplan SR, Liang MH, Luthra HS, Medsger TA Jr, Mitchell DM, Neustadt DH, Pinals RS, Schaller JG, Sharp JT, Wilder RL, Hunder GG: The American Rheumatism Association 1987 revised criteria for the classification of rheumatoid arthritis. Arthritis Rheum 1988, 31:315-324

19. Inoue $\mathrm{E}$, Yamanaka H, Hara M, Tomatsu T, Kamatani N: Comparison of Disease Activity Score (DAS)28- erythrocyte sedimentation rate and DAS28-C-reactive protein threshold values. Ann Rheum Dis 2007, 66:407-409.

20. Fransen J, van Riel PL: The Disease Activity Score and the EULAR response criteria. Clin Exp Rheumatol 2005, 23:S93-S99.

21. Darrah PA, Patel DT, De Luca PM, Lindsay RW, Davey DF, Flynn BJ, Hoff ST, Andersen P, Reed SG, Morris SL, Roederer M, Seder RA: Multifunctional $T_{H}$ cells define a correlate of vaccine-mediated protection against Leishmania major. Nat Med 2007, 13:843-850.

22. Nestorov I: Clinical pharmacokinetics of TNF antagonists: how do they differ? Semin Arthritis Rheum 2005, 34:12-18.

23. Carballo E, Lai WS, Blackshear PJ: Feedback inhibition of macrophage tumor necrosis factor-a production by tristetraprolin. Science 1998, 281:1001-1005.

24. Manicourt DH, Triki R, Fukuda K, Devogelaer JP, Nagant De Deuxchaisnes C, Thonar EJ: Levels of circulating tumor necrosis factor a and interleukin- 6 in patients with rheumatoid arthritis, Relationship to serum levels of hyaluronan and antigenic keratan sulfate. Arthritis Rheum 1993, 36:490-499.

25. Mease PJ: Adalimumab in the treatment of arthritis. Ther Clin Risk Manag 2007, 3:133-148.

26. Whitelaw DM: Observations on human monocyte kinetics after pulse labeling. Cell Tissue Kinet 1972, 5:311-317.

27. Chu CQ, Field M, Feldmann M, Maini RN: Localization of tumor necrosis factor $a$ in synovial tissues and at the cartilage-pannus junction in patients with rheumatoid arthritis. Arthritis Rheum 1991, 34:1125-1132.

28. Mitoma H, Horiuchi T, Tsukamoto H, Tamimoto $Y$, Kimoto $Y$, Uchino A, To K, Harashima S, Hatta N, Harada M: Mechanisms for cytotoxic effects of anti-tumor necrosis factor agents on transmembrane tumor necrosis factor a-expressing cells: comparison among infliximab, etanercept, and adalimumab. Arthritis Rheum 2008, 58:1248-1257. 
29. Schuerwegh AJ, Van Offel JF, Stevens WJ, Bridts CH, De Clerck LS: Influence of therapy with chimeric monoclonal tumour necrosis factor-a antibodies on intracellular cytokine profiles of $\mathrm{T}$ lymphocytes and monocytes in rheumatoid arthritis patients. Rheumatology (Oxford) 2003, 42:541-548

30. Kaymakcalan Z, Sakorafas P, Bose S, Scesney S, Xiong L, Hanzatian DK, Salfeld J, Sasso EH: Comparisons of affinities, avidities, and complement activation of adalimumab, infliximab, and etanercept in binding to soluble and membrane tumor necrosis factor. Clin Immunol 2009, 131:308-316.

doi:10.1186/ar4615

Cite this article as: Zamora-Atenza et al:: Adalimumab regulates intracellular TNFa production in patients with rheumatoid arthritis. Arthritis Research \& Therapy 2014 16:R153.

\section{Submit your next manuscript to BioMed Central and take full advantage of:}

- Convenient online submission

- Thorough peer review

- No space constraints or color figure charges

- Immediate publication on acceptance

- Inclusion in PubMed, CAS, Scopus and Google Scholar

- Research which is freely available for redistribution 